\title{
Is it possible to predict atherosclerosis in the ascending aorta by the patient's lipid panel?
}

İsmail Haberal ${ }^{1}$, Mehmet Ali Yesiltas ${ }^{2}$, Ahmet Ozan Koyuncu ${ }^{1}$, Sebnem Batur ${ }^{3}$, Sadiye Deniz Ozsoy ${ }^{1}$, Hülya A.K. Yilmaz ${ }^{4}$, Aysim Buge ${ }^{3}$

\author{
${ }^{1}$ Department of Cardiovascular Surgery, Institute of Cardiology, Istanbul University \\ Cerrahpasa, Istanbul, Turkey \\ ${ }^{2}$ Department of Cardiovascular Surgery, Bakırköy Dr.Sadi Konuk Training and Research \\ Hospital, Istanbul, Turkey \\ ${ }^{3}$ Department of Pathology, Cerrahpasa Medical Faculty, Istanbul University, Istanbul, \\ Turkey \\ ${ }^{4}$ Department of Anesthesiology and Reanimation, Institute of Cardiology, Istanbul \\ University Cerrahpasa, Istanbul, Turkey
}

Submitted: 23 May 2020

Accepted: 25 July 2020

Arch Med Sci Atheroscler Dis 2020; 5: e237-e244

DOI: https://doi.org/10.5114/amsad.2020.98940

Copyright (c) 2020 Termedia \& Banach

\section{Abstract}

Introduction: Atherosclerosis is a chronic inflammatory event characterized by stiffness and thickening of the vascular walls. In our daily practice, we assume the atherosclerotic potential of the patient by following the total cholesterol, high-density lipoprotein (HDL), low-density lipoprotein (LDL) and triglyceride levels (lipid panel). We aimed to understand the relation between the HDL, LDL, cholesterol levels and the atherosclerosis in large vascular structures such as the ascending aorta.

Material and methods: We have searched for atherosclerosis in the aortic tissue samples from 48 patients. It is a study in which we examine the correlation of preoperative cholesterol values (HDL, LDL, triglyceride, total cholesterol) by dividing the patients into two groups according to the presence of plaque.

Results: Forty-three (89.6\%) male and $5(10.4 \%)$ female patients between 39 and 81 years of age were included in the study. There was no statistically significant difference between the patients' preoperative cardiovascular risk assessments. The free T3 values were within the normal range in all patients, but there was a difference that patients in the non-atherosclerosis group had lower values. There was no statistically significant difference between the two groups' HDL, LDL, total cholesterol, or triglyceride parameters. Conclusions: As a result, in our study, no significant difference was found between HDL-C, LDL-C, triglyceride, total cholesterol values and the pathological process of aortic atherosclerosis. As a result of this study, we believe that it was necessary to correct the error margins of these parameters. In addition, it required the need for a clearer laboratory parameter to demonstrate atherosclerosis.

Key words: atherosclerosis, low-density lipoprotein cholesterol, lipid panel.

\section{Introduction}

There are many cardiovascular risk factors (CVRF), and the most important of these are diabetes mellitus (DM), smoking, high body mass index (BMI), high blood pressure and atherosclerosis [1]. The actual num-

\author{
Corresponding author: \\ Mehmet Ali Yesiltas MD \\ Bakırköy Dr. Sadi Konuk \\ Training and Research \\ Hospital \\ Istanbul, Turkey \\ E-mail: dr.maliyes@gmail.com
}


ber of patients with atherosclerosis and cardiovascular disease is quite high, even if their cardiovascular risks are low. Atherosclerosis remains an important risk factor for coronary artery disease and peripheral vascular diseases in middle-age asymptomatic patient groups where there are no other risk factors mentioned [2, 3]. In middle-age group patients with low CVRF, it is reported that if they are classified by coronary artery classification or carotid ultrasound, approximately $60 \%$ of them have subclinical atherosclerosis [4].

Atherosclerosis is a chronic inflammatory event characterized by stiffness and thickening of the vascular walls. Local vascular damage, inflammation and oxidative stress are the basis of its pathology. Vascular endothelial damage can be considered as the first step of this process. Platelet and leukocyte adhesion and lipid accumulation occur in this damaged area. These adhesive cells release endothelial-induced growth factor and therefore cause smooth muscle cell proliferation [5]. Atherosclerotic plaque has content rich in cholesterol and fatty acid. Additionally, lipoproteins are responsible for carrying cholesterol and fatty acid, which makes them significantly important for plaque build-up. The relationship between atherosclerosis and low-density lipoprotein cholesterol (LDL-C) was described in the study of Austin et al. for the first time [6]. LDL-C is a cholesterol-rich triglyceride-poor molecule. Goldstein et al. defined the LDL receptors [7], thus we now have more detailed information about LDL. It is known that there is an inverse proportional relationship between triglyceride and high density-lipoprotein cholesterol (HDL-C) levels. It is considered that $\mathrm{HDL}-\mathrm{C}$ does its work by moving cholesterol in the opposite direction. Indeed, HDL-C reduces atherosclerotic plaque build-up by protecting the LDL-C from oxidation [8]. Also, triglyceride (TG) has an effect on atherosclerosis independently from HDL-C and LDL-C. An increase in TG level causes a decrease in serum HDL-C level and an increase in LDL-C. Under normal circumstances, TG does not accumulate in the vascular wall, but it tends to pass to the sub-endothelial cavity through the damaged endothelium when TG-rich lipoprotein levels increase in blood. This pathologic accumulation increases oxidation and smooth muscle proliferation, and contributes to the formation of atheroma plaques [9]. Although the presence of well-known conventional risk factors and markers suggest atherosclerosis, oxy-reductive parameters can show signs of the vascular damage more accurately and earlier [10].

HDL-C levels are often inversely proportional to the risk of developing atherosclerosis. The main anti-atherosclerotic effect of $\mathrm{HDL}$ is thought to be reverse cholesterol transport. HDL has been shown to exhibit beneficial effects on platelet function, endothelial function, coagulation parameters and inflammation. HDL cholesterol has also been shown to have a significant antioxidant effect, which can contribute to protection from atherosclerosis [11].

The lipoproteins are the major transporters of both cholesterol and fatty acids. The LDL particles are triglyceride-poor, cholesterol-rich particles. LDL has a unique structure, being composed of a hydrophilic surface layer of phospholipid, free cholesterol and hepatically derived apo B100 to package the particle and add stability. The core of the particle includes esterified cholesterol and triglyceride together with the fatty acid tails of the phospholipid. As with most proteins in the circulation, the particle may play a role as a carrier for other insoluble particles such as free fatty acids. LDL are among the best known lipoproteins because of maintaining cholesterol homeostasis. They are also important because statins, which inhibit 3-hydroxy-3-methylglutaryl coenzyme A (HMG-CoA) reductase, the rate-limiting enzyme for cholesterol synthesis, were shown to up-regulate the LDL receptor, lower cholesterol in the blood stream and reduce cardiovascular events. Failure of this protective system causes atherosclerosis [12].

In the light of these observations, in our daily practice, we assume the atherosclerotic potential of the patient by following the total cholesterol, HDL-C, LDL-C and triglyceride levels (lipid panel). According to the patients' laboratory results, we determine our anti-atherosclerotic treatment so as to reduce cardiovascular risk. In this study, we aimed to understand the relation between the HDL, LDL, cholesterol levels and the atherosclerosis in large vascular structures such as the ascending aorta.

\section{Material and methods}

\section{Study design}

For 10 weeks starting in June 2019, we evaluated the patients who underwent coronary artery bypass grafting due to isolated coronary artery disease. Only elective cases with patients over 18 years of age were included in the study. Emergency cases and patients who had full arterial grafts were excluded from the study. HDL, LDL, triglyceride and total cholesterol levels were checked preoperatively. We have searched for atherosclerosis in the aortic tissue samples with 48 patients.

Since all patients underwent coronary revascularization, they were considered to be at a very high risk according to the 2019 ESC/EAS Guidelines for the management of dyslipidemias. Patients were divided into two groups according to the pathological examination: the atherosclerosis group and no-atherosclerosis group. We examined 
the relationship between atherosclerosis and patients' lipid panel in these two groups [13].

The ideal total cholesterol value was determined as below $200 \mathrm{mg} / \mathrm{dl}$. Total cholesterol values above $200 \mathrm{mg} / \mathrm{dl}$ were accepted as high. Triglyceride level was considered to be high if above $150 \mathrm{mg} / \mathrm{dl}$. The LDL-C value $<100 \mathrm{mg} / \mathrm{dl}$ was accepted as the ideal value and it was considered to be high if over $130 \mathrm{mg} / \mathrm{dl}$. The HDL-C value was considered to be high if above $60 \mathrm{mg} / \mathrm{dl}$ [14].

\section{Laboratory evaluation}

$8 \mathrm{ml}$ of venous blood was drawn from each patient into tubes without anticoagulants. These blood samples were left for clot formation for $20 \mathrm{~min}$ before centrifugation for a minimum of $10 \mathrm{~min}$ at 4000 rpm within total $30 \mathrm{~min}$. Total cholesterol, triglyceride, and HDL-C plasma concentrations of the serum samples were evaluated with the enzymatic chemical cleaning method using a Cobas 6000 (Roche Diagnostics $\mathrm{GmbH}$, Mannheim, Germany). LDL-C values were calculated by the Friedewald formula.

The target LDL-C value was accepted as $<55 \mathrm{mg} / \mathrm{dl}$, since all patients were considered as at very high risk [13].

\section{Sampling the ascending aortic tissue}

The proximal anastomoses of saphenous vein grafts are performed on the aorta during coronary artery bypass grafting (CABG). We chose the correct region for anastomoses after manually examining the presence or absence of hard plaque in the aortic tissue. While aortic side- or cross-clamping during the $C A B G$, a small incision was made on the aorta using no. 11 scalpels. After that, aortic tissue samples were taken using an aortic punch (IBC Aortic Punch size: 4.0 mm/4.4 mm) (Figure 1).

\section{Pathology evaluation}

The aortic tissue samples were stored with glutaraldehyde solutions under sterile conditions and taken to the pathology laboratory. Tissue samples were processed by routine clinical laboratory methods, being fixed in $10 \%$ formaldehyde and embedded in paraffin wax. Tissue sections were cut, using a microtome, at $5 \mu \mathrm{m}$ thickness, placed onto glass slides, and the sections were stained with hematoxylin and eosin (H\&E) and examined under the light microscope. Histochemical evaluation was done with orcein.

Vascular atherosclerosis was classified as AHA lesion type I, II, III, IV, V or VI plaques by two independent reviewers blinded to histopathology [15] (Figure 2, Table I). In histopathologic examination, the evaluation of type 3, 4, 5 and 6 was considered significant in terms of atherosclerosis in our study and was assigned to the atherosclerosis group.

\section{Statistical analysis}

SPSS v21.0 and Microsoft Office Excel 2016 were used for data collection and analysis. Categorical variables are expressed as frequency $(n)$ and percentage (\%), while continuous variables were expressed as mean \pm standard deviation and median (smallest-largest value). The compatibility of the data to normal distribution was evaluated

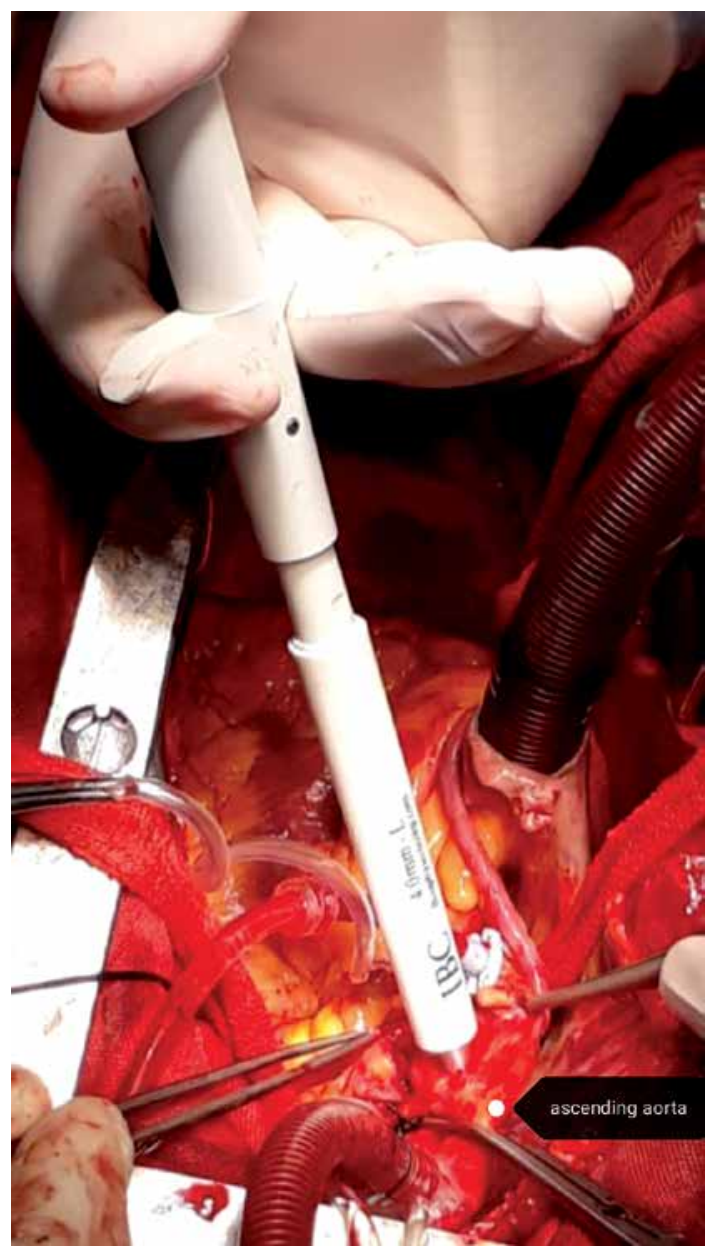

Figure 1. Aortic tissue sampling from ascending aorta with $4.0 \mathrm{~mm}$ aortic punch while CABG

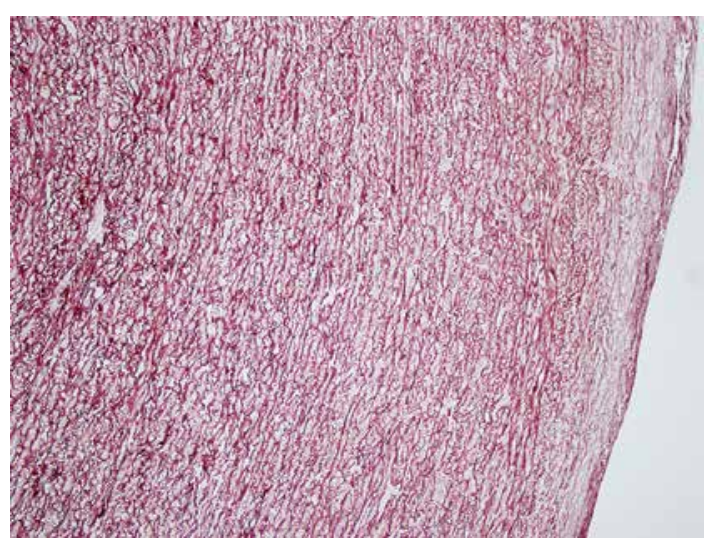

Figure 2. Dense foam cells (100x) 
Table I. Atherosclerotic lesions in histological classification (appearance with the eyes)

\begin{tabular}{|lr|}
\hline Type & \multicolumn{1}{c|}{ Lesions } \\
\hline 1 & Initial lesion (isolated macrophage foam cells) \\
\hline $2 \mathrm{a}$ & Type prone to progression of atherosclerosis (mainly intracellular lipid accumulation) \\
\hline $2 \mathrm{~b}$ & Pre-atheroma (type $2+$ small extracellular lipids pool) \\
\hline 3 & Atheroma (type $2+$ core of extracellular lipid) \\
\hline 4 & Cabro atheroma (lipid core + fibrotic layer or multiple lipid core) \\
\hline $5 a$ & Fibrotic lesion (fibrotic layer, mainly fibrotic) \\
\hline $5 b$ & Lesion with surface defect, and/or hematoma-hemorrhage, and/or thrombotic deposit \\
\hline $5 c$ & (surface defect, hematoma-hemorrhage, thrombus) \\
\hline 6 &
\end{tabular}

by the coefficient of variation, histogram curves and Shapiro-Wilk test. The $\chi^{2}$ test and Fisher's exact test were used to evaluate the difference between groups for categorical variables. The independent groups $t$ test was used if normal distribution conditions were provided in evaluating the difference between two independent groups for continuous variables. In cases where normal distribution conditions were not met, the Mann-Whitney $U$ test was used. The statistical significance value was taken as $p<0.05$ in the analyses.

\section{Results}

There were 48 cases in our study. All of these patients had an elective isolated CABG. All of them were in the very high-risk patient group according to the 2019 ESC/EAS dyslipidemia guidelines for the management of dyslipidemias. Forty-three $(89.6 \%)$ male and 5 (10.4\%) female patients between 39 and 81 years of age were included in the study.

Age, smoking, body mass index (BMI), diabetes mellitus, and hypertension were evaluated as risk factors for atherosclerosis for both groups (Table II). We found that the atherosclerosis group smoked $21.57 \pm 18.23$ packs/ year, and the group without atherosclerosis smoked $27.44 \pm 27.57$ packs/year. After evaluating the BMI, it was $26.88 \pm 4.74 \mathrm{~kg} / \mathrm{m}^{2}$ in the no-atherosclerosis group and $27.47 \pm 3.12 \mathrm{~kg} / \mathrm{m}^{2}$ in the atherosclerosis group. There was no sig-

Table II. Preoperative baseline values according to the presence of atherosclerotic plaque

\begin{tabular}{|c|c|c|c|c|c|}
\hline \multirow[t]{2}{*}{ Parameter } & \multicolumn{2}{|c|}{ No atherosclerosis } & \multicolumn{2}{|c|}{ Atherosclerosis } & \multirow[t]{2}{*}{$P$-value } \\
\hline & Mean \pm SD & Median & Mean \pm SD & Median & \\
\hline Age & $64.91 \pm 8.91$ & $65(48-83)$ & $59.50 \pm 10.54$ & $58.5(39-76)$ & $0.076^{\dagger}$ \\
\hline Smoking (pack-year) & $27.44 \pm 27.57$ & $25(0-100)$ & $21.57 \pm 18.23$ & $18.5(0-55)$ & $0.755^{*}$ \\
\hline Ejection fraction (\%) & $52.53 \pm 9.18$ & $57.5(32-60)$ & $55.07 \pm 6.12$ & $57.5(42-60)$ & $0.535^{*}$ \\
\hline Ascending aorta & $35.35 \pm 3.47$ & $35(30-45)$ & $35.07 \pm 4.78$ & $36(28-47)$ & $0.820^{\dagger}$ \\
\hline BMI [kg/m²] & $26.88 \pm 4.74$ & $26.55(20.2-40.4)$ & $27.47 \pm 3.12$ & $27.38(22.77-33.06)$ & $0.460^{*}$ \\
\hline White blood cells & $8.27 \pm 2.32$ & $8.15(4.6-14.6)$ & $8.12 \pm 2.35$ & $7.9(5.1-13)$ & $0.733^{*}$ \\
\hline Hematocrit (\%) & $38.49 \pm 4.18$ & $39.35(28.8-46.4)$ & $37.35 \pm 3.85$ & $37.7(30.44-44.3)$ & $0.383^{\dagger}$ \\
\hline Creatinine & $0.91 \pm 0.21$ & $0.9(0.5-1.69)$ & $0.90 \pm 0.34$ & $0.82(0.54-1.8)$ & $0.266^{*}$ \\
\hline $\mathrm{HbA}_{1 \mathrm{c}}(\%)$ & $5.4 \pm 0.3$ & $5.3(5.0-5.8)$ & $5.6 \pm 0.2$ & $5.4(5.0-5.9)$ & $0.518^{*}$ \\
\hline $\begin{array}{l}\text { Total cholesterol } \\
{[\mathrm{mg} / \mathrm{dl}]}\end{array}$ & $173.91 \pm 41.36$ & 165 (109-276) & $156.79 \pm 36.36$ & 149 (107-223) & $0.186^{\dagger}$ \\
\hline $\mathrm{HDL}-\mathrm{C}[\mathrm{mg} / \mathrm{dl}]$ & $41.42 \pm 12.53$ & $40(21-80)$ & $42.57 \pm 15.41$ & $36(22-67)$ & $0.735^{\star}$ \\
\hline LDL-C [mg/dl] & $115.24 \pm 40.44$ & 109 (59-210) & $99.64 \pm 29.95$ & $99.5(53-143)$ & $0.221^{*}$ \\
\hline Triglycerides [mg/dl] & $167.61 \pm 105.06$ & $144(53-528)$ & $148.21 \pm 89.68$ & $127(58-420)$ & $0.537^{*}$ \\
\hline Albumin & $4.20 \pm 1.03$ & $4.14(3.13-9.54)$ & $4.25 \pm 0.43$ & $4.19(3.62-5.01)$ & $0.266^{*}$ \\
\hline CRP & $11.71 \pm 17.48$ & $4.5(0.5-63)$ & $7.16 \pm 6.06$ & $7.4(1.1-22)$ & $0.785^{*}$ \\
\hline
\end{tabular}

${ }^{*} \chi^{2}$ test was applied. ${ }^{\dagger}$ Fisher's exact test was performed. ECO - echocardiography, BMI - body mass index, WBC - white blood cells. 
nificant difference. There were 5 diabetic patients in the atherosclerosis group and 16 in the no-atherosclerosis group. When the glycated hemoglobin $\left(\mathrm{HbA}_{1 \mathrm{c}}\right)$ values were examined, it was $5.4 \pm 0.3 \%$ in the no-atherosclerosis group and $5.6 \pm 0.2$ in the atherosclerosis group. It was also observed that diabetic patients in both groups were under control and taking adequate medical care. There was no significant difference. There were 8 patients with hypertension in the atherosclerosis group and 21 in the no-atherosclerosis group $(p=0.766)$. There was no significant difference between the risk factors for atherosclerosis in both groups (Table III). There was no statistically significant difference between the two groups' HDL, LDL, total cholesterol, and triglyceride parameters. All other preoperative results are presented in Table II. Nine (18.75\%) patients had a two-vessel bypass, 26 (54.2\%) of them three-vessel, 8 (16.7\%) of them four-vessel, 5 (10.4\%) of them five-vessel bypass. There was no statistically significant difference in the presence of atherosclerosis in any lipid panel (HDL-C, LDL-C, total cholesterol and triglyceride) (Table III).

\section{Discussion}

According to the LDL-C hypothesis, LDL-C is a causative factor in atherosclerosis. Although the hypothesis is generally accepted, controversy continues about its validality [15, 16]. Evidence supporting this hypothesis has emerged from experimental models, epidemiological cohorts, and cholesterol-lowering (mainly statin-based) clini- cal studies [17]. However, the remaining conflicts should be considered.

Many studies have shown that there is an important link between LDL-C and atherosclerotic cardiovascular disease [18]. Therefore, we consider the LDL values as we are choosing the adequate treatment. Many clinical trials recommend statin therapy to manage LDL-C levels [19-22]. We also aim to maintain the HDL at adequately higher levels. In fact, since rosuvastatin and simvastatin are thought to have the effect of increasing HDL-C, we also prefer these statins in our patient groups [23]. Therefore, it is important to determine which of these laboratory parameters play a role in the process of artery atherosclerosis. In this study, we aimed to understand the relation between $\mathrm{HDL}$, LDL, and cholesterol levels and atherosclerosis in large vascular structures such as the ascending aorta.

The American Diabetes Association (ADA) and the American College of Cardiology (ACC) arrived at a consensus and stated that non-HDL-C is a better indicator for identifying patients with high cardio-metabolic risk factors [24]. Srinivasan et al. reported that non-HDL-C levels may be useful for the determination of lipoprotein-related risks [25]. The non-HDL-C which was used in the Srinivasan et al. study was not used in our study. There might have been a statistically difference between the atherosclerosis and the non-atherosclerosis group, if it had been used. In subsequent studies, non-HDL-C will be used along with the other lipid markers. Despite the importance of LDL-C, it may

Table III. Comparison of risk factors and target levels with very high risk patients 2019 ESC/EAS dyslipidemia guidelines for the management of dyslipidemias

\begin{tabular}{|c|c|c|c|c|c|c|}
\hline \multirow[t]{2}{*}{ Parameter } & & \multicolumn{2}{|c|}{ No atherosclerosis } & \multicolumn{2}{|c|}{ Atherosclerosis } & \multirow[t]{2}{*}{$P$-value } \\
\hline & & $n$ & $\%$ & $n$ & $\%$ & \\
\hline \multirow[t]{2}{*}{ Gender } & Male & 31 & 72.09 & 12 & 27.91 & $0.621^{\dagger}$ \\
\hline & Female & 3 & 60 & 2 & 40 & \\
\hline Diabetes mellitus & & 16 & 76.19 & 5 & 23.81 & $0.471^{\star}$ \\
\hline Hypertension & & 21 & 72.41 & 8 & 27.59 & $0.766^{\star}$ \\
\hline \multirow[t]{2}{*}{ Total cholesterol } & $<200 \mathrm{mg} / \mathrm{dl}$ & 24 & 66.67 & 12 & 33.33 & $0.336^{*}$ \\
\hline & $>200 \mathrm{mg} / \mathrm{dl}$ & 9 & 81.82 & 2 & 18.18 & \\
\hline \multirow[t]{2}{*}{ HDL cholesterol } & $>45 \mathrm{mg} / \mathrm{dl}$ & 10 & 71.43 & 4 & 28.57 & $0.906^{*}$ \\
\hline & $<45 \mathrm{mg} / \mathrm{dl}$ & 23 & 69.7 & 10 & 30.3 & \\
\hline \multirow[t]{2}{*}{ LDL cholesterol } & $<55 \mathrm{mg} / \mathrm{dl}$ & 9 & 69.2 & 4 & 30.8 & $0.927^{*}$ \\
\hline & $>55 \mathrm{mg} / \mathrm{dl}$ & 24 & 70.58 & 10 & 29.42 & \\
\hline \multirow[t]{2}{*}{ Triglycerides } & $<200 \mathrm{mg} / \mathrm{dl}$ & 24 & 66.67 & 12 & 33.33 & $0.336^{*}$ \\
\hline & $>200 \mathrm{mg} / \mathrm{dl}$ & 9 & 81.82 & 2 & 18.18 & \\
\hline
\end{tabular}

${ }^{\star} \chi^{2}$ test was applied. ${ }^{\dagger}$ Fisher's exact test was performed. 
not be that cost-effective. There are many studies searching for an easy and reliable methodology for its routine use [26]. Since it is affordable and easy to use, the Friedewald formula (FF) is a convenient and widely used method. However, while using this formula, if triglyceride is over $400 \mathrm{mg} / \mathrm{dl}$, it causes the very low density lipoprotein (VLDL) to be over-calculated and the LDL-C to be under-calculated. This miscalculation raises doubts about whether LDL is truly related to atherosclerosis. In our study, there was 1 patient with triglyceride over $400 \mathrm{mg} / \mathrm{dl}$ in the atherosclerosis group and 2 patients in the non-atherosclerosis group, which was not statistically significant.

Youn et al. examined the carotid intima media layers thickness in 1700 subjects and it appeared to be associated with increased BMI and high LDL-C in healthy individuals [27]. The LDL-C value was $113.1 \pm 31.9 \mathrm{mg} / \mathrm{dl}$ in the male patients and 117.3 $\pm 32.2 \mathrm{mg} / \mathrm{dl}$ in the females. In our study, LDL mean \pm SD value was $99.64 \pm 29.95 \mathrm{mg} / \mathrm{dl}$ in the group with atherosclerosis and $115.24 \pm 40.44 \mathrm{mg} / \mathrm{dl}$ in the non-atherosclerosis group. No statistically significant difference was found between LDL-C or BMI value and presence of atherosclerosis $(p=0.221)$.

$\mathrm{Li}$ et al. examined the presence or absence of luminal stenosis atherosclerosis (LSA) with positron emission tomography (PET). While the LDL-C value of patients in the LSA group was $102.9 \pm 29.2 \mathrm{mg} / \mathrm{dl}$, it was $99.9 \pm 31.3 \mathrm{mg} / \mathrm{dl}$ in the no-LSA group ( $p=0.29$ ). While the HDL-C value was $55.8 \pm 16.5$ $\mathrm{mg} / \mathrm{dl}$ in the LSA group, it was $54.3 \pm 17.8 \mathrm{mg} /$ $\mathrm{dl}$ in the no-LSA group $(p=0.31)$. The total cholesterol value was $179.8 \pm 39.8 \mathrm{mg} / \mathrm{dl}$ in the LSA group, while it was $183.7 \pm 31.8 \mathrm{mg} / \mathrm{dl}$ in the LSA group $(p=0.22)$ There was no statistically significant difference. Similarly, in our study, LDL-C was $115.24 \pm 40.44 \mathrm{mg} / \mathrm{dl}$ in the no-atherosclerosis group, while it was $99.64 \pm 29.95 \mathrm{mg} / \mathrm{dl}$ in the atherosclerosis group $(p=0.221)$. While HDL-C was $41.42 \pm 12.53 \mathrm{mg} / \mathrm{dl}$ in the no-atherosclerosis group, it was $42.57 \pm 15.41 \mathrm{mg} / \mathrm{dl}$ in the atherosclerosis group ( $p=0.735)$. On the other hand, total cholesterol value was $173.91 \pm 41.36 \mathrm{mg} / \mathrm{dl}$ in the no-atherosclerosis group and $156.79 \pm 36.36 \mathrm{mg} /$ $\mathrm{dl}$ in the atherosclerosis group $(p=0.186)$. When all lipid panel values were compared, there was no significant difference in our study as well [28].

In a PESA study with 1779 subjects by Fernández-Friera et al. [29], patients were examined by Doppler USG or CT. More than $0.5 \mathrm{~mm}$ thickening in the intima media or $1.5 \mathrm{~mm}$ intima thickness towards the lumen in the carotid arteries or infrarenal aorta was considered as atherosclerosis. BMI was $24.5 \pm 3.3 \mathrm{~kg} / \mathrm{m}^{2}$ in the non-atherosclerosis group and $25.3 \pm 3.4 \mathrm{~kg} / \mathrm{m}^{2}$ in the group with atherosclerosis. There was no significant difference. Total cholesterol values were $187.0 \pm 24.4$ $\mathrm{mg} / \mathrm{dl}$ in the non-atherosclerosis group and 194.6 $\pm 22.9 \mathrm{mg} / \mathrm{dl}$ in the group with atherosclerosis. The LDL-C was $125.7 \pm 20.1 \mathrm{mg} / \mathrm{dl}$ versus 117.4 $\pm 21.7 \mathrm{mg} / \mathrm{dl}$. The HDL-C value was $53.5 \pm 10.1 \mathrm{mg} / \mathrm{dl}$ vs. $55.4 \pm 10.6 \mathrm{mg} / \mathrm{dl}$. The triglyceride was 63 (50-83) $\mathrm{mg} / \mathrm{dl}$ versus 68 (53-92) $\mathrm{mg} / \mathrm{dl}$. In our study, the triglyceride was $167.61 \pm 105.06 \mathrm{mg} / \mathrm{dl}$ in the non-atherosclerosis group, while it was $148.21 \pm 89.68 \mathrm{mg} / \mathrm{dl}$ in the atherosclerosis group. Total cholesterol was $173.91 \pm 41.36 \mathrm{mg} / \mathrm{dl}$ versus $156.79 \pm 36.36 \mathrm{mg} / \mathrm{dl}$. LDL-C value was 115.24 $\pm 40.44 \mathrm{mg} / \mathrm{dl}$ in the non-atherosclerosis group and it was $99.64 \pm 29.95 \mathrm{mg} / \mathrm{dl}$ in the atherosclerosis group. $\mathrm{HDL}-\mathrm{C}$ was $41.42 \pm 12.53 \mathrm{mg} / \mathrm{dl}$ versus $42.57 \pm 15.41 \mathrm{mg} / \mathrm{dl}$. In our study, no statistically significant difference was found.

There are studies showing that there is a relationship between $\mathrm{HbA}_{1 \mathrm{c}}$ and subclinical atherosclerosis. In 2,340 non-diabetic individuals, higher $\mathrm{HbA}_{1 \mathrm{c}}$ concentrations (between $5.7 \%$ and $6.4 \%)$ were associated with increased carotid intima-media thickness [30]. In an another prospective series $(n=2.652)$ with non-diabetic patients, $\mathrm{HbA}_{1 \mathrm{c}}$ in the near-highest level (> 5.7\%) was associated with progression of both carotid intima-media thickness and cardiovascular events [31]. In our study, the $\mathrm{HbA}_{1 c}$ was $5.4 \pm 0.3$ in the group without atherosclerosis and $5.6 \pm 0.2$ in the group with atherosclerosis. No statistically significant difference was found.

In a study with 91 patients, the relationship between LDL-C and the ascending aorta was examined. LDL-C was observed to have a linear relationship with the ascending aorta diameter, which was measured as $40.5 \pm 7.3 \mathrm{~mm}$. In our study, it was measured as $35.35 \pm 3.47 \mathrm{~mm}$ in the group without atherosclerosis and $35.07 \pm 4.78 \mathrm{~mm}$ in the group with atherosclerosis. However, it was not statistically significant.

In the study of Zhang et al., it was examined whether the non-HDL-C value was more sensitive than LDL-C as a marker for the severity of atherosclerosis in coronary artery patients. It was determined that non-HDL-C was more sensitive. In our study, LDL-C, total cholesterol and triglyceride values were examined and no difference was found. Although the results may look similar, non-HDL-C was not evaluated in our study. In addition, the number of patients in our study was smaller [32].

In the study of Gomez et al., the relationship between subclinical atherosclerosis and oxidized LDL in the general population was examined. Ankle-brachial index and carotid intima-media thickness were evaluated in the study. Although oxidized LDL was found to be associated with coronary artery diseases, it was found to be unrelated with carotid intima-media thickness or ankle-brachial index. Similarly, in our study, there 
was no difference found in LDL-C, total cholesterol or triglyceride values between the groups [33].

There are several limitations: an insufficient number of patients and taking tissue samples from plaque-free areas of the ascending aorta, as is required in the CABG procedure. Therefore, since this region (calcific/fibrotic plaque) is avoided, the plaque load may be considered less. In addition, although our patients' LDL values were above the target value, they were below $130 \mathrm{mg} / \mathrm{dl}$.

In conclusion, in our study, no significant difference was found between HDL-C, LDL-C, triglyceride, total cholesterol values and the pathological process of ascending aortic atherosclerosis. As a result of this study, we believe that it is necessary to correct the error margins of these parameters. In addition, there is a need for a clearer laboratory parameter to demonstrate atherosclerosis.

\section{Conflict of interest}

The authors declare no conflict of interest.

\section{References}

1. Wilson P, D'Agostino RB, Levy D, et al. Prediction of coronary heart disease using risk factor categories. Circulation 1998; 97: 1837-47.

2. Yusuf S, Rangarajan S, Teo K, et al. Cardiovascular risk and events in 17 low-, middle-, and high- income countries. N Engl J Med 2014; 371: 818-27.

3. Silverman MG, Blaha MJ, Krumholz HM, et al. Impact of coronary artery calcium on coronary heart disease events in individuals at the extremes of traditional risk factor burden: the Multi-Ethnic Study of Atherosclerosis. Eur Heart J 2014; 35: 2232-41.

4. Fernandez-Friera L, Penalvo JL, Fernandez-Ortiz A, et al. Prevalence, vascular distribution, and multiterritorial extent of subclinical athero- sclerosis in a middle-aged cohort: the PESA (Progression of Early Subclinical Atherosclerosis) study. Circulation 2015; 131: 2104-13.

5. Murphy JG. Mayo Clinic Cardiology Review. Lippincott Williams \& Wilkins 2001; 99-106.

6. Austin MA, Kraus RM. LDL density and atherosclerosis. JAMA 1995; 373: 115

7. Goldstein JL, Brown MS. The LDL receptor. Atherioscler Thromb Vasc Biol 2009; 29: 431-8.

8. Kontush A, Chapman MJ. Antiatherogenic function of HDL particle subpopulations: focus on antioxidative activities. Curr Opin Lipidol 2010; 21: 312-8.

9. Ravi GR, Pradeepa R, Mohan V. Hypertriglyceridemia and coronary artery disease-an update. Indian Heart J 2004; 56: 21-6.

10. Majer M, Gackowski D, Różalski R, Siomek-Górecka A, Oliński R, Budzyński J. Systemic oxidoreductive balance and vascular function in individuals without clinical manifestation of atherosclerosis. Arch Med Sci Atheroscler Dis 2017; 2: 37-45.

11. Bandeali S, Farmer J. High-density lipoprotein and atherosclerosis: the role of antioxidant activity. Curr Atheroscler Rep 2012; 14: 101-7.

12. Linton MRF, Yancey PG, Davies SS, et al. The role of lipids and lipoproteins in atherosclerosis. Endotext [Internet] 2019.
13. Mach F, Baigent C, Catapano AL, et al. 2019 ESC/EAS Guidelines for the management of dyslipidaemias: lipid modification to reduce cardiovascular risk; The Task Force for the management of dyslipidaemias of the European Society of Cardiology (ESC) and European Atherosclerosis Society (EAS). Eur Heart J 2020; 41: 111-88.

14. Jellinger PS, Handelsman Y, Rosenblit PD, et al. American Association of Clinical Endocrinologists and American College of Endocrinology Guidelines for management of dyslipidemia and prevention of cardiovascular disease - executive summary. Complete Appendix to Guidelines available at http://journals.aace.com. Endocr Pract 2017; 23: 479-97.

15. Ravnskov U, Diamond DM, Hama R, et al. Lack of an association or an inverse association be- tween low-density-lipoprotein cholesterol and mortality in the elderly: a systematic review. BMJ Open 2016; 6: e010401.

16. Ference BA, Ginsberg HN, Graham I, et al. Low-density lipoproteins cause atherosclerotic cardiovascular disease. 1. Evidence from genetic, epidemiologic, and clinical studies. A consensus statement from the European Atherosclerosis Society Consensus Panel. Eur Heart J 2017; 38: 2459-72.

17. Jarcho JA, Keaney JF Jr. Proof that lower is better - LDL cholesterol and IMPROVE-IT. N Engl J Med 2015; 372: 2448-50.

18. Stamler J, Wentworth D, Neaton JD. Is relationship between serum cholesterol and risk of premature death from coronary heart disease continuous and graded? findings in 356,222 primary screenees of the Multiple Risk Factor Intervention Trial (MRFIT). JAMA 1986; 256: 2823-8.

19. MRC/BHF Heart Protection Study Investigators. MRC/ BHF Heart Protection Study of cholesterol lowering with simvastatin in 20,536 high-risk individuals: a randomised placebo-controlled trial. Lancet 2002; 360: 7-22.

20. Downs JR, Clearfield M, Weis S, et al. Primary prevention of acute coronary events with lovastatin in men and women with average cholesterol levels: results of AFCAPS/TexCAPS. AirForce/Texas Coronary Atherosclerosis Prevention Study. JAMA 1998; 279: 1615-22.

21. Long-Term Intervention with Pravastatin in Ischaemic Disease (LIPID) Study Group. Prevention of cardiovascular events and death with pravastatin in patients with coronary heart disease and a broad range of initial cholesterol levels. N Engl J Med 1998; 339: 1349-57.

22. Nissen SE, Tuzcu EM, Schoenhagen P. Statin therapy, LDL cholesterol, C-reactive protein, and coronary artery disease. N Engl J Med 2005; 352: 29-38.

23. Barter PJ, Brandrup-Wognsen G, Palmer MK. Effect of statins on HDL-C: a complex process unrelated to changes in LDL-C: analysis of the VOYAGER Database. J Lipid Res 2010; 51: 1546-53.

24. Brunzell JD, Davidson M, Furberg CD, et al. Lipoprotein management in patients with cardiometabolic risk: consensus conference report from the American Diabetes Association and the American College of Cardiology Foundation. J Am Coll Cardiol 2008; 51: 1512-24.

25. Srinivasan SR, Myers L, Berenson GS. Distribution and correlates of non-high density lipoprotein cholesterol in children: the Bogalusa Heart Study. Pediatrics 2002; 110: e29.

26. Smets EML, Pequeriaux NCV, Blaton V, Goldschmidt HMJ. Analytical performance of a direct assay for LDL-cholesterol. Clin Chem Lab Med 2001; 39: 270-80.

27. Youn YJ, Lee NS, Kim JY, et al. Normative values and correlates of mean common carotid intima-media thick- 
ness in the Korean rural middle-aged population: the Atherosclerosis Rlsk of Rural Areas in Korea General Population (ARIRANG) study. J Korean Med Sci 2011; 26: 365-71.

28. Li L, Ge Y, Wan X, Wu K, Liu D. Positron emission tomographic studies of the association between atherogenesis and aortitis among psoriatic patients. Arch Med Sci 2020. DOI: https://doi.org/10.5114/aoms.2020.94983.

29. Fernández-Friera L, Fuster V, López-Melgar B, et al. Normal LDL-cholesterol levels are associated with subclinical atherosclerosis in the absence of risk factors. J Am Coll Cardiol 2017; 24: 2979-91.

30. Xing FY, Neeland IJ, Gore MO, et al. Association of prediabetes by fasting glucose and/or haemoglobin A1c levels with subclinical atherosclerosis and impaired renal function: observations from the Dallas Heart Study. Diab Vasc Dis Res 2014; 11: 11-8.

31. Sander D, Schulze-Horn C, Bickel H, Gnahn H, Bartels E, Conrad B. Combined effects of hemoglobin A1c and $\mathrm{C}$-reactive protein on the progression of subclinical carotid atherosclerosis: the INVADE study. Stroke 2006; 37: 351-7.

32. Zhang Y, Wu NQ, Li S, et al. Non-HDL-C is a better predictor for the severity of coronary atherosclerosis compared with LDL-C. Heart Lung Circ 2016; 25: 975-81.

33. Gómez M, Vila J, Elosua R, et al. Relationship of lipid oxidation with subclinical atherosclerosis and 10-year coronary events in general population. Atherosclerosis 2014; 232: 134-40. 